\section{Marcia Fajer'}

Ildeberto Muniz de Almeida"

Frida Marina Fischer"II

Programa de Pós-Graduação em Saúde Pública. Faculdade de Saúde Pública (FSP) Universidade de São Paulo. São Paulo, SP, Brasil

" Departamento de Saúde Pública. Faculdade de Medicina de Botucatu. Universidade Estadual Paulista. Botucatu, SP, Brasil

III Departamento de Saúde Ambiental. FSPUSP. São Paulo, SP, Brasil

\section{Correspondence:}

Marcia Fajer

R. do Rocio, 450, Apto 12 C - Vila Olímpia 04552-000 São Paulo, SP, Brasil

E-mail: mcafajer@usp.br

\section{Contributive factors to aviation accidents}

\begin{abstract}
The objective of the study was to compare the results of aviation accident analyses performed by the Center for Investigation and Prevention of Aviation Accidents (CENIPA) with the method Human Factors Analysis and Classification System (HFACS). The final reports of thirty-six general aviation accidents occurring between 2000 and 2005 in the State of São Paulo, Southeastern Brazil were analyzed and compared. CENIPA reports mentioned 163 contributive factors, while HFACS identified 370 factors. It was concluded that CENIPA reports did not contemplate the organizational factors associated with aviation accidents.
\end{abstract}

DESCRIPTORS: Accidents, Aviation Accidents, Occupational Accidents. Evaluation. Risk Factors.

\section{INTRODUCTION}

Aviation is a transportation activity that involves different levels of operation and interrelated tasks, some highly complex and subject to various occupational stressors. $^{4}$

The state of São Paulo, Southeastern Brazil, concentrates the bulk of aerial activity in the Country, mainly of general aviation, including training, executive, air-taxis, special air services, and agricultural aviation aircrafts.

The analysis of aircraft accidents in Brazil is carried out by the military Centro de Investigação e Prevenção de Acidentes Aeronáuticos (CENIPA - Center for Investigation and Prevention of Aviation Accidents), based on the International Civil Aviation Organization laws. These analyses deal with grouped factors (material, operational, and human), resulting in a multiple causes view of accidents. Still, these studies are restricted to the man-machine system, and failures resulting from organizational issues are not investigated.

Reason $^{3}$ (2005) believes that accidents result from combinations that are not always predictable, from human and organizational factors within a complex system. His organizational accident model explains these events with the occurrence of failures or absent defenses and safeguards in the system developed to minimize the chance of accidents. Active failure occurs near the accident outcome involving the behavior (decisions, actions, or omissions) of operators and are difficult to predict and control. These active failures originate in latent conditions related to technical and organizational factors present in the system well before accidents occur. Reason's model also includes a demonstration of the possibility of accidents occurring without active failures, i.e., triggered directly from interactions between latent conditions. ${ }^{1}$

Based on Reason's model, the Human Factors Analysis and Classification System (HFACS) has been used to analyze accidents since it can identify a great number of contributing factors. ${ }^{4}$ 
This study aimed to compare the results of the investigations of Brazilian general aviation accidents by CENIPA with the HFACS model.

\section{METHODS}

We used the final reports of accidents involving general aviation aircrafts in São Paulo between the years of 2000 and 2005, concluded by CENIPA until December 2008. This state was chosen because it has the largest percentage of aircrafts in the country (28\%), including all categories of "general aviation". Commercial aviation was excluded because of major differences in its operation.

Data were obtained from final reports issued by CENIPA with information on aviation accidents: accident data [history, damage caused, personnel involved, aircraft, weather conditions, navigation, communications, airfield, crash, wreck, fire, survival, flight recorders, operational aspects, human factors (physiological and psychological)], and what was investigated (analyses, conclusions and flight safety recommendations). Data on contributing factors of accidents in these final CENIPA reports were obtained from the "conclusion".

The HFACS model used was based on Shappell et al ${ }^{4}$ (2007) and is supported by Reason's Theory. ${ }^{3}$ This model was chosen for comparison with CENIPA's because it has been used in the investigation of general aviation accidents in the United States and enables an evaluation of a larger number of contributing factors.

The factors considered in the HFACS model are: organizational influences (organizational climate, organizational process, resource management), unsafe supervision (inadequate supervision, planned inappropriate operations, failed to correct problems, supervisory violations), preconditions for unsafe acts (environmental, physical, and technological factors), condition of operators (adverse mental and physiological states, physical/mental limitations), personnel factors (crew resource management and personal readiness), and unsafe acts (decision errors, skill-based errors, perceptual errors, routine and exceptional violations).

\section{RESULTS}

During the period, there were 74 general aviation accidents. For 38 of these, the final reports had not yet been released, leaving us with a total of 36 to analyze. Final reports were thus distributed: $2000(27.8 \%) ; 2001$ (22.2\%); 2002 (19.5\%); 2003 (16.7\%); 2004 (11.1\%) and $2005(2.8 \%)$.

The distribution of cases by category of operations showed that $44.5 \%$ involved private air service operators, $25 \%$ private instruction aircrafts, $16.7 \%$ special air services, $11.1 \%$ air taxi, and $2.8 \%$ public air transport.
These accidents involved 114 people, of which 50\% were crewmembers, $41.2 \%$ passengers, and $8.8 \%$ other victims. A total of $42.1 \%$ resulted in fatal injuries, $8.7 \%$ led to severe injuries, $26.3 \%$ to mild, and $22.8 \%$ of cases were unharmed.

The distribution by type of occurrence was: engine failure in flight $(33.3 \%)$, mid-air collision with obstacle $(30.5 \%)$, loss of control in flight $(16.7 \%)$, loss of control in soil $(5.5 \%)$, failure of control in flight $(2.8 \%)$, weather phenomenon $(2.8 \%)$, collision with obstacles in soil $(2.8 \%)$, system failure $(2.8 \%)$ and spacial disorientation $(2.8 \%)$.

Contributing factors as noted in the final CENIPA reports were categorized as: human factors (10.4\%) and operational factors $(89.6 \%)$. No failures due to material factors were identified. The total number of contributing factors in the CENIPA model was 163, resulting in an average of 4.52 factors per accident. The distribution of these factors, considering the frequency of citations were: misjudgment $(80.5 \%)$, poor planning (66.7\%), poor supervision $(66.7 \%)$, psychological aspects (44.4\%), flight indiscipline $(38.9 \%)$, poor cockpit coordination (30.5\%), adverse weather conditions $(25 \%)$, lack of experience $(22.2 \%)$, poor control application (22.2\%), other operational aspects (19.4\%), poor maintenance $(16.7 \%)$, poor instruction $(8.3 \%)$, influence of the environment $(5.5 \%)$, forgetfulness $(2.8 \%)$ and physiological aspect $(2.8 \%)$.

The total number of contributing factors in the HFACS model was 370 , averaging 10.3 per accident, with the following distributions by categories according to types of events: unsafe acts $(36 \%)$, unsafe supervision $(28.3 \%)$, organizational influences $(18.1 \%)$, and preconditions for unsafe acts (17.6\%) (Figure).

\section{DISCUSSION}

The main contributing factors seen in the HFACS and CENIPA analytical models were "misjudgment" and "decision error". In both methods, the main factor was failure by operators (pilots) and secondly, poor supervision in the CENIPA model, and unsafe supervision in the HFACS. It is possible that the high frequency of failures attributed to supervision in both cases reflects the influence of traditional practices in the training of analysts and their experience.

The results suggest that security be understood as a product of adherence to rules and/or to the right way of doing things, and that such practices be ensured, among other things, by training and supervision. ${ }^{2}$

The small proportion of cases attributed to mechanical failure is consistent with the literature dealing with the histories of aviation and safety. Pariès \& Amalberti ${ }^{5}$ showed that accident rates tend to be higher in the 


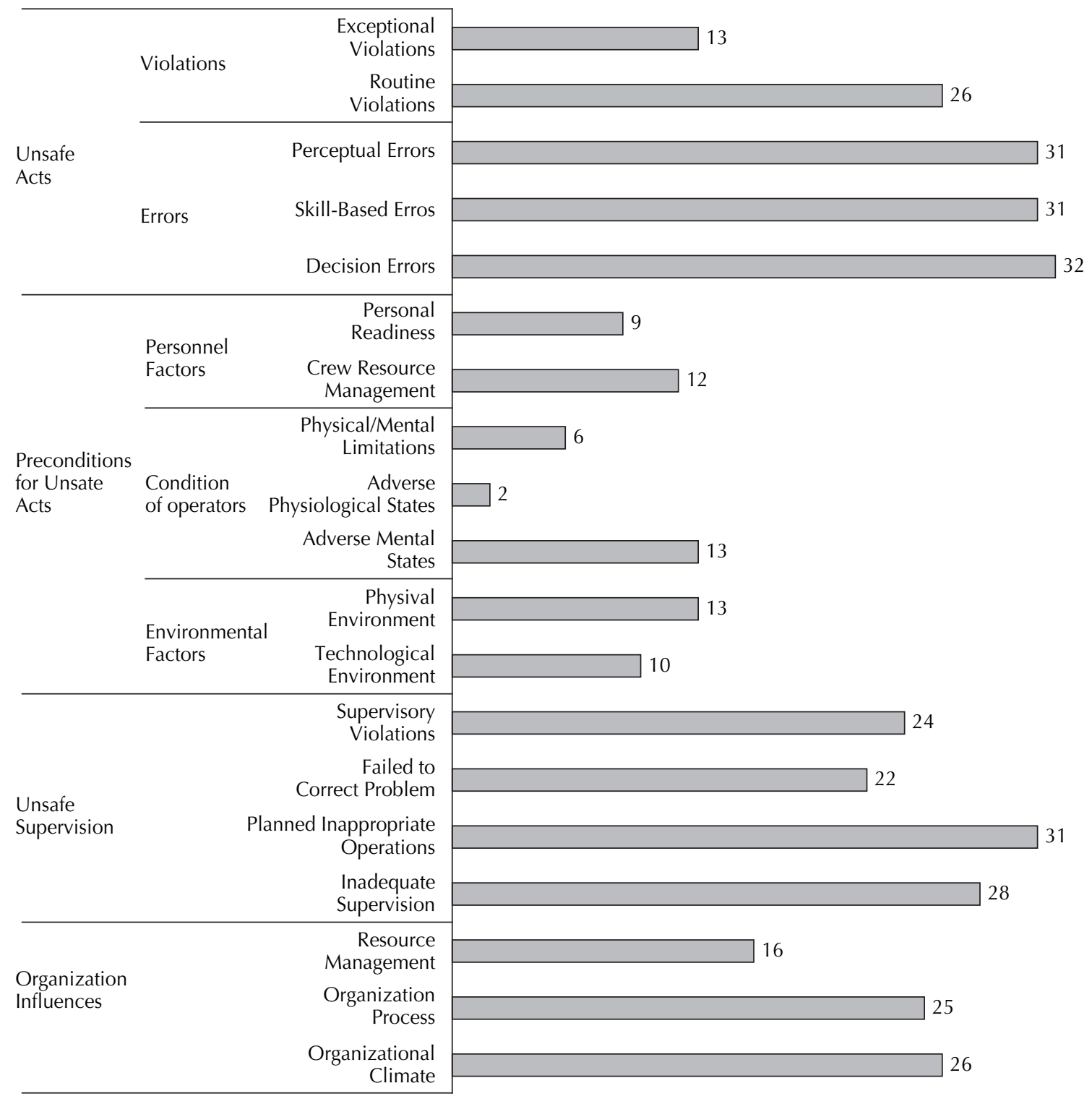

Figure. Number of contributing factors for general aviation accidents according to the Human Factors Analysis and Classification System. State of São Paulo, Southeastern Brazil, 2000-2005.

first years after the introduction of new technologies, followed by rapid reductions to levels below those obtained in the previous situation.

The low average number (less than five) of contributing factors in accidents by the CENIPA analysis shows that accidents tend to be addressed as simple events with few causes, given the number of associated factors. This happens when the analysis tends to focus on factors close to the outcome of the accident, without exploring its origins in depth or without adopting explicit procedures for systematic data collection and organization of findings. ${ }^{1}$

According to the HFACS, these accidents had a higher average number of contributing factors; more than twice that of CENIPA. HFACS also identified organizational factors related to human resource management that the CENIPA assessment failed to observe. This difference can be explained partly by the fact that the HFACS model supports the exploration and systematic organization of findings.

According to Leveson, ${ }^{2}$ accident investigation should take broad view of the incident and include information to increase the perimeter of analysis beyond proximal events, exploring structural deficiencies in organization and management deficiencies, as well as failures in the safety culture within the system or society.

The findings on organizational influences in the analysis conducted with the HFACS method should 
initially be interpreted as evidence of the effective contribution of aspects from this dimension in the origins of accidents analyzed.

From the CENIPA list of contributing factors, we should highlight aspects centered on people and those represented in the group of operational factors. The CENIPA analysis considered the latter together with others from the group of human factors. The creation of instruments for accident analysis able to explain both the relational nature and the existence of interactions between various technical devices on the behavior in work situations is still a challenge.

One of the practical contributions of this study is that the way air accidents are analyzed, particularly in the model used by CENIPA, shows no evidence that the system is appropriating the contributions of studies that emphasize the need to explain the accidents. In other words, it is not exploring the latent or incubated origins of these events in the history of the system, or still, discussing these findings with the help of disciplines such as Social Sciences, Cognitive Psychology, Ergonomics, Anthropology, and Engineering Systems.

\section{REFERENCES}

1. Almeida IM. Trajetória da análise de acidentes: o paradigma tradicional e os primórdios da ampliação da análise. Interface (Botucatu). 2006;10(19):185-202. DOI:10.1590/S1414-32832006000100013.

2. Leveson NG. A new approach to system safety engineering. Massachusetts: Institute of Technology; 2002.

3. Reason J. Safety in the operating theatre - Part 2: Human error and organizational failure. Qual Saf Health Care. 2005;14(1):56-60.

4. Shappell S, Detwiler C, Holcomb K, Hackworth C, Boquet A, Wiegmann DA. Human error and commercial aviation accidents: an analysis using the human factors analysis and classification system. Human Factors. 2007;49(2):227-42. DOI:10.1518/001872007X312469

5. Pariès J, Amalberti R. Aviation Safety Paradigms and Training Implications In: Sarter NB, Amalberti R. Cognitive Engineering in the Aviation Domain. London: Lawrence Erlbaum Associates Publishers; 2000. p. 253-286.

The authors declare that there are no conflicts of interest. 